CLINICAL PICTURE

\title{
Chondroma in an Elderly Patient
}

\author{
Salvador Labrador*, Jose Manuel Llamazares-Medrano and Jesús Guzmán-Revuelta
}

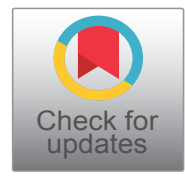

Health Center of Bezana, Spain

*Corresponding author: Salvador Labrador, Primary Care, Health Center of Bezana, Avenida Menendez Pelayo 11, 39110 Santa Cruz de Bezana, Cantabria, Spain

\section{Introduction}

A 68-year-old male patient presented to our Clinic with unilateral knee pain for a period of 5 months. He was following treatment with NSAID and Omeprazole with no good outcome. We performed an X-ray on the symptomatic knee (Figures 1 and Figure 2) and we observed in the Metaphysis of distal Femur a heavily calcified lesion, well demarcated and evenly distributed throughout. Recent Laboratory tests were unremarkable. We concluded that this lesion could correspond to a Chondroma of distal Femur.

\section{Age and Gender}

The Chondromas occur in individuals up to the age of 50 but rarely below the age of 10 [1] and more prevalent in Men [2].

\section{Symptoms}

Chondromas are benign tumors composed of mature hyaline cartilage and generally asymptomatic. Many are discovered incidentally on Roentgenographic examination. Pain unassociated with pathological Fracture should arise the suspicion of Malignancy [2] but the erosive characteristic may cause Pain and swelling. Those Chondromas on the long bones have a greater but still only slight tendency to undergo malignant transformation [1].

\section{Roentgenographic Features}

Chondromas produce a localized, central region of rarefaction they also occur less commonly in long bones and in the pelvic and shoulder girdles, in which sites they have a greater tendency to become malignant [3].
Any portion of the bones may be involved but in the long bones these Tumors tend to be Metaphyseal as in our Clinical case (Figure 1). The amount of calcification varies from slight to marked. Ossification within the lesion may make it radiopaque. Mineralization is usually uniformly distributed throughout the lesion [2]. Calcification of the matrix or new bone formation may produce an area of increased density within the lesion. The appearance of the new bone varies from dense sclerosis that obliterates all evidence of normal trabeculae to

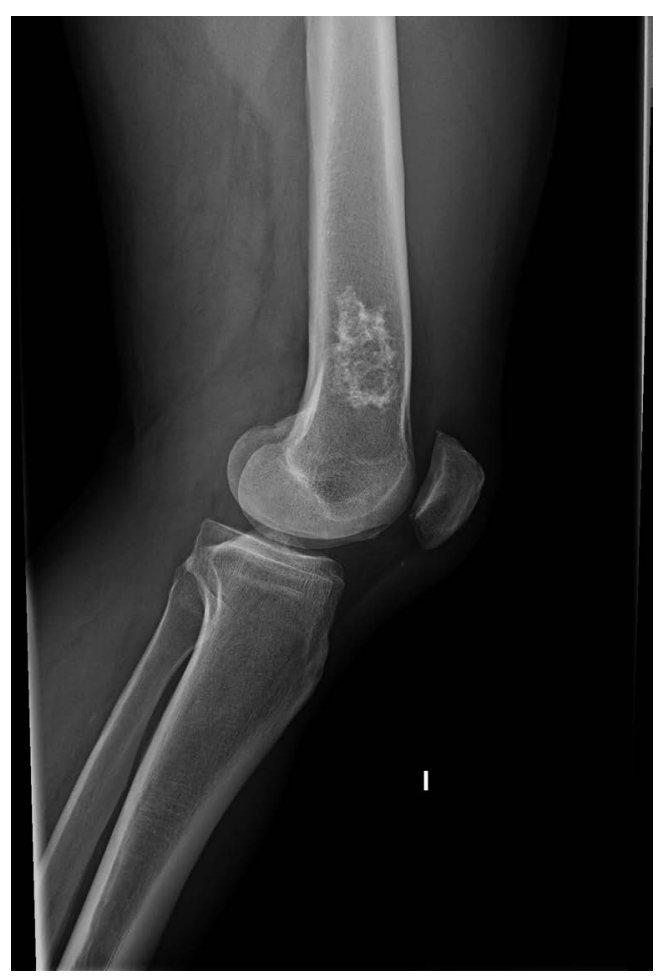

Figure 1: Lateral View of Knee (X-Ray-Roentgen ).

Citation: Labrador S, Llamazares-Medrano JM, Guzmán-Revuelta J (2020) Chondroma in an Elderly Patient. Clin Arch Bone Joint Dis 3:011. doi.org/10.23937/2643-4091/1710011

Accepted: May 25, 2020: Published: May 27, 2020

Copyright: (c) 2020 Labrador S, et al. This is an open-access article distributed under the terms of the Creative Commons Attribution License, which permits unrestricted use, distribution, and reproduction in any medium, provided the original author and source are credited. 


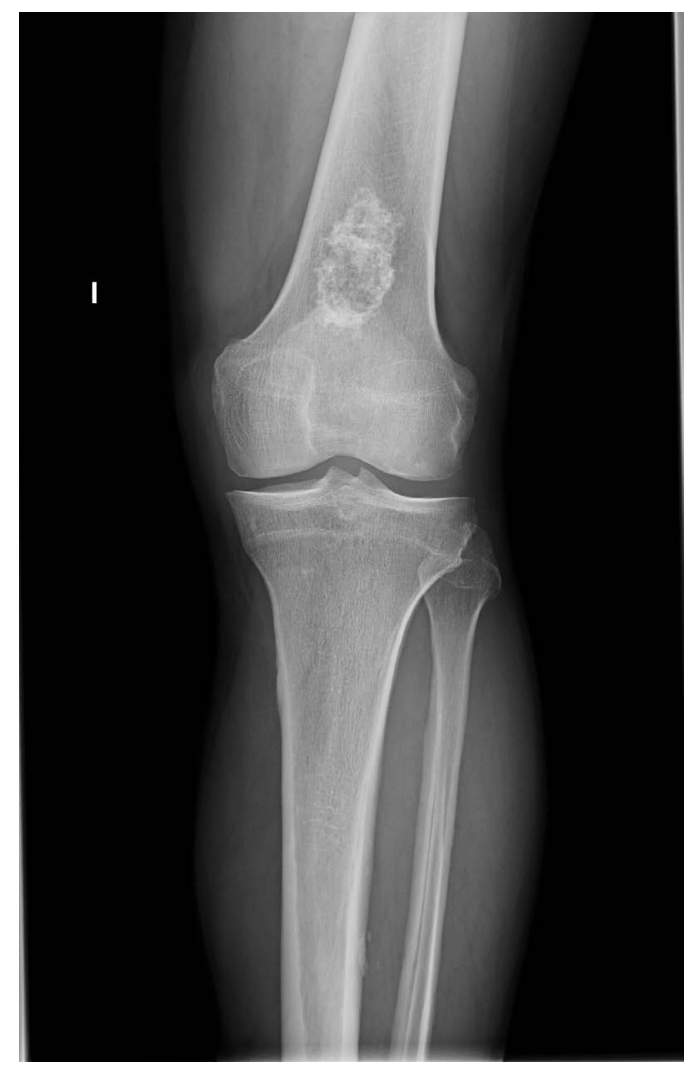

Figure 2: Anterior-Posterior View of Knee (X-Ray-Roentgen).

small irregular circumscribed masses described as wool or clouds. Neither type of matrix formation, calcification or ossification, per se are diagnostic of malignancy [4] (Figures 1 and Figure 2).

Histologically, Foci of calcification and even ossification are sometimes encountered in the cartilage, but bone formation is not enclosed within a fibrous stroma, differentiating such osteoid deposition from that found in osteogenic sarcomas [1]. The bony cortex overlying a long bone chondroma is uninvolved [2].

\section{Differential Diagnosis}

Several Bone Tumors may be taken into account in a Differential Diagnosis. Chondrosarcomas which are extremely unusual in this location permeates through the cortex into soft tissues and are usually painful. They tend to occur in an older age group and are preponderant in males. In many cases the patient has a history of a mass present for years supporting the belief that these lesions arise frequently in pre-existing benign tumors
[1]. Periosteal chondromas tend to be small. The lesions tend to be on the surface of the bone, with scalloping of the Underlying cortex. In several conditions multiple chondroid lesions may be seen in the skeleton. They are called Multiple Chondromas such as in Ollier and Maffucci syndromes. In Maffucci Syndrome in addition to the bony lesion, soft tissue hemangiomas are present and may be seen in on plain Roentgenograms because of Fleboliths. Bone infarcts may resemble calcifying cartilaginous neoplasm's, but infarcts typically are centrally lucent and well separated from surrounding normal bone by a zone of calcification or even ossification at their peripheries. Enchondromas have generally mineralization in the central regions. Soft tissue Chondrosarcomas occur very rarely in these locations and are common in the hands and feet and are usually benign. Synovial Chondromatosis is an unusual non-neoplastic condition of the joints in which nodules of metaplastic cartilage are present within the synovium but patients are usually young adults and complain of pain or limitation of movement of the involved joints [2].

\section{Treatment}

Solitary chondromas of long or flat bones, which may be incidental findings, need no treatment. Because chondromas, by definition, do not involve the cortex, pathologic fractures should not occur. If by chance a chondroid lesion appears benign on Roentgenograms but raises suspicion of Malignancy, it should be removed completely rather than Biopsied [2].

\section{Surveillance}

In our clinical case, this Elderly Male patient with knee pain and Roentgenographic image could be attributed to a Chondroma of distal Femur. Regular follow ups for Symptoms raising malignancy and Roentgenograms should be taken into account.

\section{References}

1. Robbins SL (1969) Pathology. (3 ${ }^{\text {rd }}$ edn), WB Saunders Company, 1346-1348.

2. Krishnan Unni K (1996) Dahlins Bone Tumors. Lippincott Raven Publishers. ( $5^{\text {th }}$ edn), 25-29.

3. Anderson JR (1985) Muir s Textbook of Pathology. (12 ${ }^{\text {th }}$ edn), Arnold Publishers.

4. De Vita V, Helman S, Rosenberg SA (2005) Cancer, Principles \& Practice of Oncology. ( $7^{\text {th }}$ edn), Lippincott Williams $\&$ Wilkins. 